\title{
Oral Health Behaviours and Attitudes using the Modified Arabic Version of Hiroshima University - Dental Behavioural Inventory (HU-DBI) among Sudanese Dental Students
}

Review Article

\author{
Khalid $\mathrm{K}^{1^{*}}$, Naidoo $\mathrm{S}^{2}$, Elamin $\mathrm{FI}^{3}$ \\ ${ }^{1}$ Faculty of Dentistry, University of Science and Technology, Omdurman, Sudan. \\ ${ }^{2}$ Community Dentistry, University of Western Cape, Private Bag Tygerberg, Cape Town, Western Cape, ZA, South Africa. \\ ${ }^{3}$ College of Dentistry, Jazan University, Kingdom of Saudi Arabia.
}

\section{Abstract}

\begin{abstract}
The aim of the present study was to evaluate self-reported oral health attitudes and behaviours among undergraduate Sudanese dental students and to compare differences in oral health behaviours and attitudes related to gender and level of dental education. A modified Arabic version of HU-DBI questionnaire was used to collect the data and the Statistical Package for Social Sciences $\left(\right.$ SPSS $\left.^{\circledR}\right)$ version 22 was used. One thousand two hundred and forty three dental students $(297$ male, 946 female) aged $20.1+1.8$ years were participated in this study. Overall, the findings of the current study showed that Sudanese dental students in clinical years were more aware of oral health care than those of preclinical years. Apparently, Oral health care behaviour and attitudes of Sudanese females dental students were better than males. General speaking as shown in this study indicate better oral health behaviours and attitudes among Sudanese dental students than their regional and international counterparts.
\end{abstract}

\section{Introduction}

The oral health behaviours and attitudes of dental students reflect their understanding of preventive measures and defines their ability to instruct the communities/populations they serve [1, 2]. Dental students are expected to be good examples for oral health behaviours as to be positive role models for their patients, families, and friends [3].

During the period of collecting the data of this study in 2011, there were only twelve dental schools registered in the Ministry of Higher Education in Sudan. The majority (11) are located in Khartoum State, and one in Wad-Medani, Al-Gazeira State [4].

The Sudanese dental curriculum consists of five academic years, divided into preclinical years (years 1, 2, 3) and clinical years (year $4,5)$. All dental students are introduced to preventive dentistry in the clinical years, except in Al-Gazeera University which started teaching community dentistry program from the first school year.

The Hiroshima University-Dental Behavioural Inventory (HU-
DBI) questionnaire developed by Kawamura [5] has been demonstrated to be useful for assessing patients ' perceptions and oral health behaviour and is a useful standard for cross-cultural comparisons of dental students between populations [3]. It had been translated to English, French, Italian, Korean, Chinese and many other languages [6].

Although oral health attitudes and behaviours of dental students have been evaluated in many countries using Hiroshima University-Dental Behavioural Inventory (HU-DBI) scale [1-3, 5, 6], only one similar study had been done among Sudanese dental students [7]. The aim of the present study was to evaluate self-reported oral health attitudes and behaviours among undergraduate Sudanese dental students and to compare differences in oral health behaviours and attitudes related to gender and level of dental education.

\section{Methodology}

This was a cross-sectional study. Data was collected from dental students registered in nine faculties of dentistry involved in the

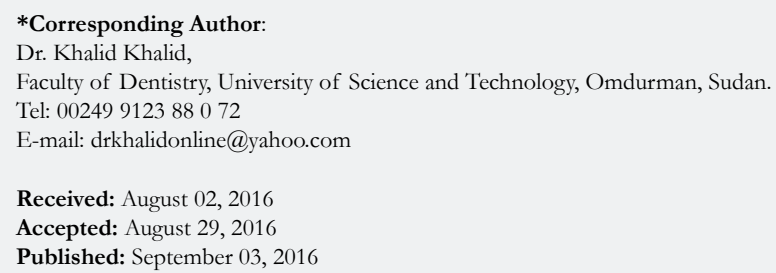

Citation: Khalid K, Naidoo S, Elamin FI (2016) Oral Health Behaviours and Attitudes using the Modified Arabic Version of Hiroshima University - Dental Behavioural Inventory (HU-DBI) among Sudanese Dental Students. Int J Dentistry Oral Sci. 3(9), 326-330. doi: http://dx.doi.org/10.19070/2377-8075-1600065

Copyright: Khalid $\mathbf{K}^{\circ}$ 2016. This is an open-access article distributed under the terms of the Creative Commons Attribution License, which permits unrestricted use, distribution and reproduction in any medium, provided the original author and source are credited. 
study. Only those who were willing to participate and who provided signed informed consent were included in the study. Ethical clearance for the study was obtained from the University of Medical Science and Technology, Khartoum, Sudan. A modified Arabic version of HU-DBI questionnaire was used to collect the data and the Statistical Package for Social Sciences $\left(\mathrm{SPSS}^{\circledR}\right)$ version 22 was used for the data analysis.

\section{Translation and Validation of questionnaire}

An English version of the HU-DBI questionnaire (Appendix 1) was submitted to a committee of two dental academics from the Faculty of Dentistry - University of Khartoum (Sudan). Each member gave a separate Arabic translated version. Then both of them jointly gave one final translated Arabic version (forward translation). This translated version was then translated back into English language by a professional English translator (backward translation). The final Arabic version was obtained by the researcher after comparing the two English versions (the original and the translated one); hence this final Arabic version was endorsed as the working questionnaire (Appendix 2).

\section{Reliability testing of the Arabic translated version of $\mathrm{HU}$ - DBI}

Data for testing the reliability of the translation was collected by two linguists from Oxford Institute (Sudan). They were asked to answer the English version and then the Arabic version of the HU-DBI separately at different times (interval of 24 hours). Reliability of the translated version was measured by percentage coincidence. There was a high level of reliability between bilinguists responses to the questionnaire in the English version compared with the Arabic version (97.75\%).

\section{Results}

Nine faculties of dentistry participated in this study. A total of 1243 dental students was involved. The largest number of participants was from Khartoum University $(n=273)$ representing $22 \%$, followed by Al-Gazeira University $(\mathrm{n}=196)$ representing 15.8 $\%$ (Table 1) and the smallest was from the National University $(n=44)$ representing $3.5 \%$ of the student population. The majority were females $(n=946)$ representing $76.1 \%$. The male: female ratio was 1:3.2 in the present study (Table 2 ).

The majority of the participants were from the fourth year $(n=286)$ and the least from the first year $(n=202)$. Just over $50 \%$ ( $n=676 ; n=163$ male and 513 female) were in the preclinical years (first, second and third year of study) and the remainder $(n=567)$ in the clinical years (fourth and fifth year) (Table 2).

Item 3 ('I worry about the color of my teeth') showed the highest percentage of participant agreement $(91.7 \%)$ while the least percentage $(6 \%)$ agreement was to item 5 ('I use a child-sized toothbrush') (Table 3). The analysis of the "agree" responses according to stage of education is shown in Table 4. Statistically significant differences $(p<0.05)$ were found for 8 items of HUDBI. For item 2 (My gums tend to bleed when I brush my teeth), item 4 (I have noticed some white sticky deposits on my teeth), item 10 (I have never taught professionally how to brush), item 11 (I think I can clean my teeth well without using toothpaste), item 12 (I often check my teeth in a mirror after brushing), item 13 (I worry about having bad breath), item 14 (It is impossible to prevent gum disease with tooth brushing alone), item 15(I put off going to the dentist until I have toothache), item 17 (I use a tooth brush with hard bristle) and item 22 (I do use mouth wash on regular basis) of HU-DBI statistically significant differences $(\mathrm{p}<0.05)$ were found between dental students in preclinical and

Table 1. The distribution of Sample according to university affiliation.

\begin{tabular}{|c|c|c|}
\hline University & Frequency & Percent (\%) \\
\hline Khartoum University & 273 & 22 \\
\hline Al-Gazeira University & 196 & 15.8 \\
\hline National Ribat University & 177 & 14.2 \\
\hline Africa International University & 177 & 14.2 \\
\hline University of Science and Technology & 125 & 10.1 \\
\hline University of Medical Sciences and Technology & 117 & 9.4 \\
\hline Al Razi University & 69 & 5.6 \\
\hline Al Nelein University & 65 & 5.2 \\
\hline National University & 44 & 3.5 \\
\hline Total & $\mathbf{1 2 4 3}$ & $\mathbf{1 0 0}$ \\
\hline
\end{tabular}

Table 2. The distribution of Sample according to Level of study and gender.

\begin{tabular}{|c|c|c|c|c|c|c|}
\hline \multirow{2}{*}{ Dental level of education } & \multicolumn{2}{|c|}{$\mathbf{N}$} & \multicolumn{4}{|c|}{ Gender } \\
\cline { 2 - 7 } & \multicolumn{2}{|c|}{} & \multicolumn{2}{c|}{ Males } & \multicolumn{2}{c|}{ Females } \\
\cline { 2 - 7 } & Frequency & $\mathbf{0}$ & $\mathbf{N}$ & $\mathbf{0}$ & $\mathbf{N}$ & $\mathbf{\%}$ \\
\hline Preclinical & 676 & 54.4 & 163 & 24.1 & 513 & 75.9 \\
\hline Clinical & 567 & 45.6 & 134 & 23.6 & 433 & 76.4 \\
\hline Total & 1243 & 100 & 297 & 23.9 & 946 & 76.1 \\
\hline
\end{tabular}


Table 3. Percentage of overall "Agree" responses among participants.

\begin{tabular}{|c|c|c|}
\hline & $\begin{array}{c}\text { Frequen- } \\
\text { cy }\end{array}$ & $\begin{array}{c}\text { Percent } \\
\mathbf{( \% )}\end{array}$ \\
\hline Item 1 & 484 & 38.9 \\
\hline Item 2 & 223 & 17.9 \\
\hline Item 3 & 1140 & 91.7 \\
\hline Item 4 & 501 & 40.3 \\
\hline Item 5 & 74 & 6.0 \\
\hline Item 6 & 446 & 35.9 \\
\hline Item 7 & 932 & 75.0 \\
\hline Item 8 & 460 & 37.0 \\
\hline Item 9 & 1100 & 88.5 \\
\hline Item 10 & 541 & 43.5 \\
\hline Item 11 & 113 & 9.1 \\
\hline Item 12 & 881 & 70.9 \\
\hline Item 13 & 1030 & 82.9 \\
\hline Item 14 & 846 & 68.1 \\
\hline Item 15 & 814 & 65.5 \\
\hline Item 16 & 89 & 7.2 \\
\hline Item 17 & 374 & 30.1 \\
\hline Item 18 & 425 & 34.2 \\
\hline Item 19 & 858 & 69.0 \\
\hline Item 20 & 592 & 47.6 \\
\hline Item 21 & 173 & 13.9 \\
\hline Item 22 & 313 & 25.2 \\
\hline
\end{tabular}

Table 4. Percentage of "Agree" responses according level of education.

\begin{tabular}{|c|c|c|c|c|}
\hline & Pre - Clinical $\left(1^{\text {st }}, 2^{\text {nd }} \& 3^{\text {rd }}\right.$ year $)$ & $\begin{array}{c}\text { Clinical } \\
\left(4^{\text {th }} \& 5^{\text {th }} \text { year }\right)\end{array}$ & Total & $P$ value \\
\hline Item 1 & $277(41.0 \%)$ & $207(36.5 \%)$ & $484(38.9 \%)$ & 0.108 \\
\hline Item 2 & $144(21.3 \%)$ & $79(13.9 \%)$ & $223(17.9 \%)$ & $* 0.001$ \\
\hline Item 3 & $627(92.8 \%)$ & $513(90.5 \%)$ & $1140(91.7 \%)$ & 0.147 \\
\hline Item 4 & $291(43.0 \%)$ & $210(37.0 \%)$ & $501(40.3 \%)$ & $* 0.031$ \\
\hline Item 5 & $37(5.5 \%)$ & $37(6.5 \%)$ & $74(6.0 \%)$ & 0.435 \\
\hline Item 6 & $229(33.9 \%)$ & $217(38.3 \%)$ & $446(35.9 \%)$ & 0.108 \\
\hline Item 7 & $500(74.0 \%)$ & $432(76.2 \%)$ & $932(75.0 \%)$ & 0.367 \\
\hline Item 8 & $258(38.2 \%)$ & $202(35.6 \%)$ & $460(37.0 \%)$ & 0.356 \\
\hline Item 9 & $603(89.2 \%)$ & $497(87.7 \%)$ & $1100(88.5 \%)$ & 0.395 \\
\hline Item 10 & $331(49.0 \%)$ & $210(37.0 \%)$ & $541(43.5 \%)$ & $* 0.0001$ \\
\hline Item 11 & $66(9.8 \%)$ & $47(8.3 \%)$ & $113(9.1 \%)$ & 0.368 \\
\hline Item 12 & $498(73.7 \%)$ & $383(67.5 \%)$ & $881(70.9 \%)$ & $* 0.018$ \\
\hline Item 13 & $585(86.5 \%)$ & $445(78.5 \%)$ & $1030(82.9 \%)$ & $* 0.0001$ \\
\hline Item 14 & $486(71.9 \%)$ & $360(63.5 \%)$ & $846(68.1 \%)$ & $* 0.002$ \\
\hline Item 15 & $483(71.4 \%)$ & $331(58.4 \%)$ & $814(65.5 \%)$ & $* 0.0001$ \\
\hline Item 16 & $43(6.4 \%)$ & $46(8.1 \%)$ & $89(7.2 \%)$ & 0.233 \\
\hline Item 17 & $254(37.6 \%)$ & $120(21.2 \%)$ & $374(30.1 \%)$ & $* 0.0001$ \\
\hline Item 18 & $255(37.7 \%)$ & $170(30.0 \%)$ & $425(34.2 \%)$ & 0.004 \\
\hline Item 19 & $468(69.2 \%)$ & $390(68.8 \%)$ & $858(69.0 \%)$ & 0.865 \\
\hline Item 20 & $323(47.8 \%)$ & $269(47.4 \%)$ & $592(47.6 \%)$ & 0.905 \\
\hline Item 21 & $89(13.2 \%)$ & $84(14.8 \%)$ & $173(13.9 \%)$ & 0.403 \\
\hline Item 22 & $212(31.4 \%)$ & $101(17.8 \%)$ & $313(25.2)$ & $* 0.0001$ \\
\hline
\end{tabular}

* Difference is statistically significant $\mathrm{P}<0.05$. 
clinical years.

There were statistically significant differences $(p<0.05)$ between females and males in items 3 (I worry about the colour of my teeth), item 7 (I am bothered by the colour of my gum), item 9 (I brush each of my teeth carefully), item 11 (I think I can clean my teeth well without using toothpaste), item 12 (I often check my teeth in a mirror after brushing), item 17 (I use a tooth brush with hard bristle), item 19 ( I feel I sometimes take too much time to brush my teeth) and item 22 (I do use mouth wash on regular basis) (Table 5).

\section{Discussion}

Although English is the language of teaching and communication in the Sudanese dental schools, the Arabic language was chosen for the HU-DBI questionnaire used in the present study since it was the mother tongue for almost all the students. This study was pioneer in translating and validating an Arabic version of HU-DBI. Moreover, the wide range of difference in social, demographic, economic and ethnic background of the participants gave it more importance and representation than other Sudanese study [7].

Sudanese dental students answered positively to 17 items of modified HU-DBI questionnaire with a mean score of 7.7 which is higher than that of Polychronopoulos et al., [8] who found the mean score among Japanese students of 7.40 and that of their
Greek peers 6.68. Furthermore, Kawamura et al., [9] found the mean HU-DBI score of first year Australian dental students significantly greater than their Japanese peers (Australian 6.56, Japanese 5.57). The mean score of this study was also higher than the other Sudanese study [7] (5.08). This variance in results might related to the representative sample of this research which included dental students from nine different universities comparing with the other study [7] which included only one university.

There were significant differences between preclinical and clinical students hence dental behaviours and attitudes improved as they advanced in their studies. This finding was in agreement with the findings of Barrieshi-Nusair et al., [1], Dagli et al., [3], Pecker et al., [10] and Dumitrescu et al., [11]. On the other-side, this outcome is contradicted with Sharda et al., [12], who concluded that "knowledge is not enough to influence the oral health behaviour". Nevertheless, for item 22 ('I do use mouth wash on regular base') there was a statically significant difference $(p<0.05)$ between the preclinical and the clinical years (Table 4). This may be explained by the fact that clinical students have the knowledge that the longterm use of mouthwashes has adverse effects. Also, preclinical students were more concerned than clinical students with item 13 ('I worry about having bad breath'), and this could be due to the fact that the clinical students had more knowledge on how to overcome the problem than the preclinical students. Although some opinions might postulated that students backgrounds might even affect their oral health attitude regardless to the knowledge they had gained, Khami et al., [13] went to a result concluded that "Education and training in preventive measures should be

Table 5. Percentage of "Agree" responses according to gender.

\begin{tabular}{|c|c|c|c|c|}
\hline & Male & Female & Total & P value \\
\hline Item 1 & $123(41.4 \%)$ & $361(38.2 \%)$ & $484(38.9 \%)$ & 0.316 \\
\hline Item 2 & $56(18.9 \%)$ & $167(17.7 \%)$ & $223(17.9 \%)$ & 0.638 \\
\hline Item 3 & $253(85.2 \%)$ & $887(93.8 \%)$ & $1140(91.7 \%)$ & $* 0.0001$ \\
\hline Item 4 & $120(40.4 \%)$ & $381(40.3 \%)$ & $501(40.3 \%)$ & 0.968 \\
\hline Item 5 & $19(6.4 \%)$ & $55(5.8 \%)$ & $74(6.0 \%)$ & 0.711 \\
\hline Item 6 & $100(33.7 \%)$ & $346(36.6 \%)$ & $446(35.9 \%)$ & 0.363 \\
\hline Item 7 & $202(68.0 \%)$ & $730(77.2 \%)$ & $932(75.0 \%)$ & $* 0.001$ \\
\hline Item 8 & $100(33.7 \%)$ & $360(38.1 \%)$ & $460(37.0 \%)$ & 0.172 \\
\hline Item 9 & $251(84.5 \%)$ & $849(89.7 \%)$ & $1100(88.5 \%)$ & $* 0.014$ \\
\hline Item 10 & $132(44.4 \%)$ & $409(43.2 \%)$ & $541(43.5 \%)$ & 0.714 \\
\hline Item 11 & $46(15.5 \%)$ & $67(7.1 \%)$ & $113(9.1 \%)$ & $* 0.0001$ \\
\hline Item 12 & $194(65.3 \%)$ & $687(72.6 \%)$ & $881(70.9 \%)$ & $* 0.016$ \\
\hline Item 13 & $247(83.2 \%)$ & $783(82.8 \%)$ & $1030(82.9 \%)$ & 0.875 \\
\hline Item 14 & $195(65.7 \%)$ & $651(68.8 \%)$ & $846(68.1 \%)$ & 0.308 \\
\hline Item 15 & $198(66.7 \%)$ & $616(65.1 \%)$ & $814(65.5 \%)$ & 0.624 \\
\hline Item 16 & $27(9.1 \%)$ & $62(6.6 \%)$ & $89(7.2 \%)$ & 0.139 \\
\hline Item 17 & $110(37.0 \%)$ & $264(27.9 \%)$ & $374(30.1 \%)$ & $* 0.003$ \\
\hline Item 18 & $115(38.7 \%)$ & $310(32.8 \%)$ & $425(34.2 \%)$ & 0.059 \\
\hline Item 19 & $191(64.3 \%)$ & $667(70.5 \%)$ & $858(69.0 \%)$ & $* 0.044$ \\
\hline Item 20 & $138(46.5 \%)$ & $454(48.0 \%)$ & $592(47.6 \%)$ & 0.646 \\
\hline Item 21 & $36(12.1 \%)$ & $137(14.5 \%)$ & $173(13.9 \%)$ & 0.305 \\
\hline Item 22 & $91(30.6 \%)$ & $222(23.5 \%)$ & $313(25.2 \%)$ & $* 0.013$ \\
\hline
\end{tabular}

* Difference is statistically significant $\mathrm{P}<0.05$. 
effective enough to overcome background characteristics". Back to Al-Shiekh et al., [7] they found that no significance difference between preclinical and clinical dental students regarding oral health behavior and attitude. This outcome was limited to only one university. So based on our results, we suggested that the effectiveness of oral health curriculum in this institute should be revisited.

For some items as depicted in Table 5, females showed statistically significant difference regarding their oral health, whereas items 11, 17 and 22 showed significantly that males neglected and were more careless about their oral health than females.

From the present study it can be summarized that female Sudanese dental students take better care and are more concerned about the appearance of their teeth and had a better behaviours and attitudes towards their oral hygiene than their male peers. This finding concurs with local, regional and international studies. Al-Shiekh et al., [7] declared that Females showed a significantly higher score than males related to oral health behaviour and attitudes. Moreover, Kateeb et al., [14] found that female students had more positive dental health attitudes and behaviours than males. Also, Al-Ansari et al., [15] reported that oral health knowledge was statically significant among Kuwait females dental students than males. Furthermore, Dumitrescu et al., [11], Kawamura et al., [9], Polychronopulou et al., [8], all reported that females had better oral health attitudes than males. However, Dagli et al., [3], and Kawamura et al., [16], found no significant difference in gender regarding oral status and hygiene.

\section{Conclusions}

Overall, the findings of the current study indicate better oral health behaviours and attitudes among Sudanese dental students than their regional and international counterparts. Sudanese dental students in clinical years were more aware of oral health care than those of preclinical years. Oral health care behaviour and attitudes of Sudanese females dental students were better than males. However, it may be beneficial if oral health prevention and promotion courses were started earlier in the dental school's curriculum.

\section{References}

[1]. Barrieshi-Nusair K, Alomari Q, Said K (2006) Dental health attitudes and behaviour among dental students in Jordan. Community Dent Health. 23(3): $147-51$.

[2]. Al-Wahadni AM, Al-Omiri MK, Kawamura M (2004) Differemances in self-reported oral health behaviour between dental students and dental technology/dental hygiene students in Jordan. J Oral Sci. 46(3):191-7.

[3]. Dagli RJ, Tadakamadla S, Dhanni C, Duraiswamy P, Kulkarni S (2008) Self-reported dental health attitude and behaviour of dental students in India. J Oral Sci. 50(3): 267-72.

[4]. Admission competition guidance for higher education institutes in Sudan for the academic year 2010 - 2011.

[5]. Kawamura M (1988) Dental behavioural science: the relationship between perceptions of oral health and oral status in adults. J Hiroshima Univ Dent Soc. 20(2): 273-86.

[6]. Komabayashi T, Kawamura M, Kim KJ, Wright FA, Declerck D, et al. (2006) The hierarchical cluster analysis of oral health attitudes and behaviour using the Hiroshima University--Dental Behavioural Inventory (HUDBI) among final year dental students in 17 countries. Int Dent J. 56(5): 310-6.

[7]. Al-Shiekh L, Muhammed MED, Muhammed AER, El-Huda MA, Hashim NT (2015) Evaluation of dental students' oral hygiene attitude and behavior using HU-DBI in Sudan. Science Postprint 1(2): e00040. doi:10.14340/ spp.2015.01A0001.

[8]. Polychronopoulou A, Kawamura M, Athanasouli T (2002) Oral self-care behaviour among dental school students in Greece. J Oral Sci. 44(2): 73-8.

[9]. Kawamura M, Iwamoto Y, Wright FA (1997) A Comparison of self-reported dental health attitudes and behaviour between selected Japanese and Australian students. J Dent Educ. 61(4): 354-60.

[10]. Peker I, Alkurt MT (2009) Oral Health Attitudes and Behaviour among a Group of Turkish Dental Students. Eur J Dent. 3(1): 24-31.

[11]. Dumitrescu AL, Kawamura M, Sasahara H (2007) An assessment of oral self-care among Romanian dental students using the Hiroshima UniversityDental Behavioural Inventory. Oral Health Prev Dent. 5(2): 95-100.

[12]. Sharda AJ, Shetty S (2010) A comparative study of oral health knowledge, attitude and behaviour of non-medical, para-medical and medical students in Udaipur city, Rajasthan, India. Int J Dent Hyg. 8(2): 101-9.

[13]. Khami MR, Virtanen JI, Jafarian M, Murtomaa H (2007) Oral health behaviour and its determinants amongst Iranian dental students. Eur J Dent Educ. 11(1): 42-7.

[14]. Kateeb E (2010) Gender-specific oral health attitudes and behaviour among dental students in Palestine. East Mediterr Health J. 16(3): 329-33.

[15]. Al-Ansari JM, Honkala S (2007) Gender differences in oral health knowledge and behaviour of the health science college students in Kuwait. J Allied Health. 36(1): 41-6.

[16]. Kawamura M, Takase N, Sasahara H, Okada M (2008) Teenagers' oral health attitudes and behaviour in Japan: comparison by sex and age group. J Oral Sci. 50(2): 167-74. 